\title{
Comparative Effects of Mineralogical Differences on the Flotation Behavior of Complex Sulphide Ores
}

\author{
O. O. Ola-omole and W. Nheta
}

\begin{abstract}
Comparative effects of mineralogical differences on the flotation behavior of complex sulphide ores was investigated. The ores were sourced from Anka, North East and Ishiagu, South East Nigeria. The samples were pulverized and sieved using $\sqrt{2}$ method to select the standard set of sieves to determine their economic liberations. Particle sizes $150,106,75$ and $53 \mu \mathrm{m}$ were selected for chemical analysis by ICP-OES. Thereafter, the samples were characterized by XRD and SEM-EDS. Finally, Froth flotation was carried out on the samples in accordance with ISO 23499-2008. The results show that the size range of economic liberation for the two deposits falls between $-150+106$ $\mu \mathrm{m}$. The chemical analyses revealed that both deposits contain $\mathrm{Pb}, \mathrm{Zn}$, $\mathrm{Fe}, \mathrm{Cu}, \mathrm{Si}, \mathrm{S}, \mathrm{Na}$ and $\mathrm{Ca}$ at various percentages. $\mathrm{X}$ ray diffraction patterns of both deposits show the phases of galena, sphalerite and quartz. However, Anka deposit revealed the presence of arsenic while Ishiagu revealed magnetite. The SEM-EDS show that $\mathrm{Pb}, \mathrm{Zn}, \mathrm{Fe}, \mathrm{Al}$, $\mathrm{Si}$ and $\mathrm{Cu}$ are common to both deposits while Anka contains barite and molybdenum. From the flotation results, lead sulphide recovery was $87.74 \%$ and $85.76 \%$ for Ishiagu and Anka ore respectively. The sphalerite recovery of $88.48 \%$ was recorded against Ishiagu whilst $85.77 \%$ was recorded for Anka ore.
\end{abstract}

Keywords - Collectors, Depressant. Flotation, Mineralogical composition

\section{INTRODUCTION}

Mineralogy had been a vital tool in the study of flotation behaviour of sulphide minerals [1] - [3]. Sulphide minerals are not easy to process because of complexity in their mineralogical composition. They are sometimes composed of minerals, which are not easily differentiated from one another because of closeness in their characteristics. Processing minerals of this nature without the understanding of the mineralogy can be a waste of time and resources. Not only can deposits be complex, the valuable minerals in the ore can be of low grade rendering the deposit not viable and uneconomical to

Manuscript received October 7, 2020.

O. O. Ola-omole, is with Mineral Processing Research and Technology center Metallurgy Department, University of Johannesburg, South Africa.

W. Nheta, is with Mineral Processing Research and Technology center Metallurgy Department, University of Johannesburg, South Africa. process. According to [4], sulphide mineral are any member or group of compound with one metal component as well as Sulphur. Their structures are always simple and they are mostly metallic in nature and they conduct electricity.

Chemical and physical structures of major sulphide have been studied by various authors [1] - [4]. Five major sulphide minerals are galena, sphalerite, chalcopyrite, and pyrite [4]. These minerals are well known to be abundantly sufficient in the earth's crust and they are referred to as rock forming minerals. Most high grade deposit have been depleted giving rise to interest in the exploitation of low grade ores to extract base metals. Owing to ever increasing demand for metals, there is need to continuously exploit sulphide minerals and this give rise to studying the mineralogy for effective processing [5]. Froth flotation has been an effective methods for processing sulphide minerals because of its ability to separate effectively. Generally, the variability in the mineralogical composition is a major factor, to consider when floating sulphide ore.

Flotation depends on the ability or the inability of a mineral particle to adhere to air bubbles in the course of separation which means a portion must be rendered hydrophobic while the other portion is rendered hydrophilic [6], [7]. This is achieved by the engagement of reagents the most important of which are collectors. Other reagents are frother, $\mathrm{pH}$ modifiers, activators and depressants. Collectors are either ionizing or non-ionizing and the non-ionizing are divided into non-polar hydrocarbons which do not dissociate. However, the ionizing collectors are either cationic or anionic. The anionic are the oxydryl based and the organic, and the sulpho acid groups. These are the carboxylic sulphates and the sulphonates. However, the second class of the anionic are the sulphydril based on bivalent Sulphur. The two classes of this group are the xanthate and dithiophosphates. Xanthates are used for metal sulphides, fatty acids are for metal oxide, hydroxides and carbonates, while amines are for silicates [8].

In flotation of sulphide minerals, selectivity can be improved with addition of activators, for example, copper sulphate can be used to activate zinc in the flotation of minerals of lead, zinc and copper occurring together. Lead can be depressed by dextrin, soluble starch or sodium silicate. In the case of oxides and silicates occurring together, both cationic and anionic collectors are combined together for the flotation. [9].

$\mathrm{pH}$ is another important factor that affects the floatability. Some mineral responds well to flotation in acidic media while some floats well in alkaline media. Mineralogy also determine 
$\mathrm{pH}$ of the pulp because the composition of the ore is a criteria for choosing what media to effectively carry out successful flotation. Therefore, there is need for proper understanding of the mineral composition of any deposit before processing it. In the flotation of sulphide ore containing copper, lead and zinc, the flotation process must be carried out under a well-controlled $\mathrm{pH}$. The first stage will be to float copper at $\mathrm{pH}$ of 6 during this stage, the lead and zinc must be depress because they will not float very well at lower $\mathrm{pH}$. The second stage will be for floating lead while zinc is still depressed. Then the $\mathrm{pH}$ will be raised to say between 7.5 and 9 by adding lime. The final stage will be to float zinc. The $\mathrm{pH}$ will be raised to up to 10.5 to 11 while cooper sulphate will be added to re activate the zinc [10].

The two deposits have not been fully explored for mineral processing. A few authors have studied the geology of the areas. [11] studied the geochemical of gold deposit in the area while [12] explored the In vitro Bio accessibility of lead in artisanal mining contaminated soils and sediments from the same area.

The thrust for this work centers on the comparative analysis of the effects of mineralogy on flotation of two deposits (Anka and Ishiagu) from Nigeria. There is need to study how theses deposits respond to processing as a result of variation in their mineralogy.

\section{Procedure For PAPER Submission}

\section{A, Sample preparation.}

The sulphide mineral ores used for this study was sourced from Anka North West (50 5' E and $6008^{\prime} \mathrm{E}$ and $11051^{\prime} \mathrm{N}$ and $\left.12008^{\prime} \mathrm{E}\right)$ Nigeria. The ores were pulverized with the laboratory jaw crusher to reduce the pebbles to all passing 1 inch which was the minimum size of the set. The resulting products were sieved to remove under size particles while the oversize samples were transferred to Denver ball mill for further milling. After milling, the samples were thoroughly mixed together separately to obtain homogenous mixture. The ground samples were divided into four parts using the Jones Riffler. One portion of each product was used for particle sizing. The sieves Endecott standard set, were arranged in a stack of descending order of aperture using the $\sqrt{2}$ method to select successive sieves and the retained particles on each sieves were weighed and recorded for particle size analyses.

\section{B. Determination of chemical compositions}

Chemical compositions of the samples were carried out with Inductively Coupled Plasma Optical Emission Spectroscopy ICP-OES, ICP 9000. Based on the economic liberation from the particle size analyses, particle size fractions of $+150,-150$ $+106,-106+75$ and $-53 \mu \mathrm{m}$ were selected for ICP-OES analyses. $3 \mathrm{~g}$ of each particle size fraction were weighed and digested in aqua regia of 3:1 $\mathrm{HCl}: \mathrm{HNO}_{3}$. The suspension was digested for 16 hours at room temperature and at $1300^{\circ} \mathrm{C}$ for two hours to give it enough time to digest. It was later filtered and the filtrate was made up to $100 \mathrm{mls}$ by adding deionized water and the resulting products were taken for the analyses.

\section{Characterization by XRD}

$\mathrm{X}$-ray diffractometry was used to determine the mineral phases of the ores and this was carried out for quantitative and qualitative analyses. The powdered samples were separately prepared by back loading system. Ring shaped sample holders were degreased with acetone after which the samples were introduced to them just to fill the cups to the brim. All the samples were then loaded at the same time into the machine, XRD PANanalytical Empyrean. The PANalytical Empyrean diffractometer was equipped with Pixel detector and fixed slits with Fe filtered $\mathrm{Co}-\mathrm{K} \alpha$ radiation. The phases were identified using X'Pert High score plus software. The relative phase amounts (weights \%) were estimated using the Rietveld method.

\section{Morphological and quantitative analyses}

Morphological and quantitative analyses of the samples were carried out to determine the morphology, grain size, structure, shapes, and associations of major and minor elements embedded in the minerals. The SEM-EDS was carried out with the field emission microscope JEOL JSM 7600 SEM and a spatter coating machine. The SEM provides the information for the physical properties of the minerals while the EDS provides the information on their chemistry. The samples were coated with iridium to minimize the effects of charging during the analyses of the samples.

\section{E. Study of flotation behaviour of Anka and Ishiagu sulphide} ores.

Flotation tests were carried out on Anka and Ishiagu sulphide minerals in accordance with ISO 23499-2008 to compare the effect of mineralogy on the flotation behaviour on the two deposits. The pulp was made up of $40 \%$ solids of the sulphide ore, transferred into the flotation tank and agitated at speed of $1500 \mathrm{rpm}$ to form a homogenous pulp. The initial $\mathrm{pH}$ of the pulp was checked with electronic $\mathrm{pH}$ meter. The $\mathrm{pH}$ was adjusted to 9.50 by adding lime $(\mathrm{CaO})$. The agitation was allowed for 5 minutes followed by the adding $0.02 \mathrm{~g} \mathrm{ZnSO}_{4}$ to depress zinc present in the pulp followed by addition of $0.05 \mathrm{~g}$ Potassium Amyl Xanthate (PAX), collector and $0.2 \mathrm{mls}$ of Methyl Isobutyl Carbinol (MIBC) as frother. The pulp was aerated for 3 minutes and the froth collected as the first concentrate. Thereafter, $1 \mathrm{ml}$ of $0.5 \mathrm{M} \mathrm{NaOH}$ was added to condition the pulp before adding $1 \%$ solution of soluble starch to depress lead. $\mathrm{CuSO} 4$ was added to activate the zinc. Another installment of the collector and frother were added and the pulp was aerated and collected as the second concentrate. The flotation process was repeated with other different collectors (Sodium oleate and Sodium Ethyl Xanthate, SEX) and depressants (Potassium dichromate and sodium silicate). The recovered concentrates were collected and dried and analyzed.

\section{RESULTS}

\section{A. Economic liberation of Anka and Ishiagu sulphide minerals}

Figures 1 (a) and (b) show the economic liberation of Anka and Ishiagu sulphide minerals. Although there was variation in their particle size distributions, their economic liberations were very close. 

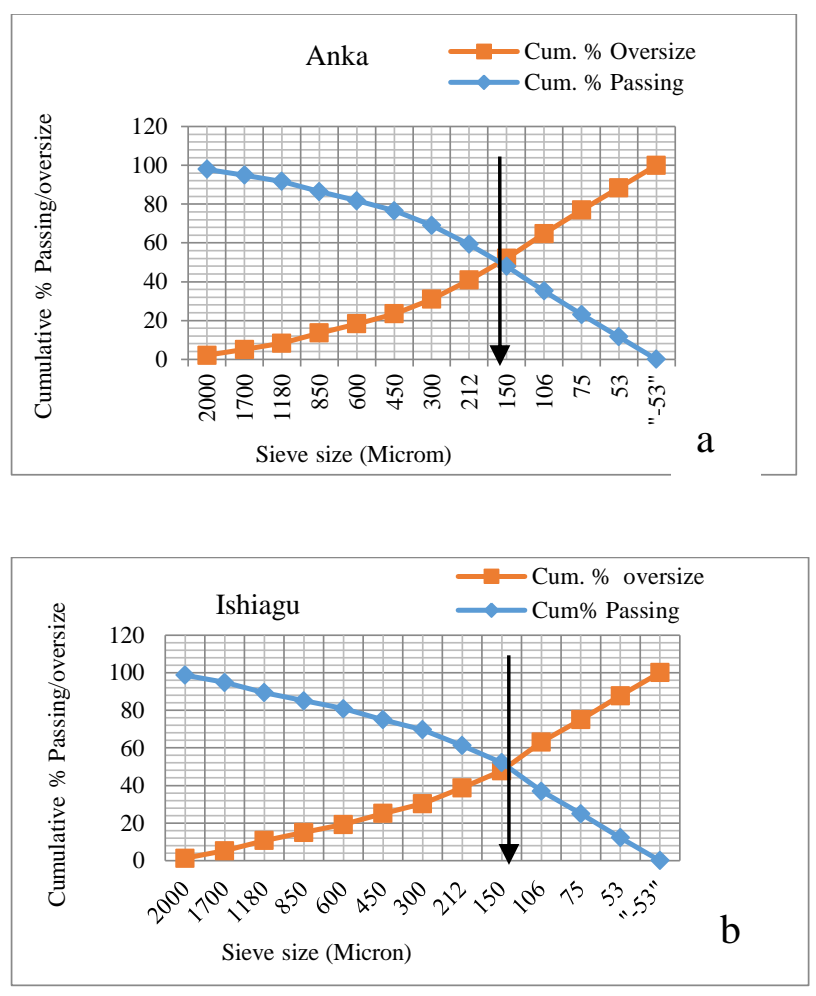

Fig 1: Sieve analysis plot of (a) Anka and (b) Ishiagu sulphide minerals showing the point of economic liberation.

The economic particle size range is $-150+106 \mu \mathrm{m}$ meaning that before processing the minerals, comminution must take place to crush the sample to all passing $150 \mu \mathrm{m}$. Economic liberation determines at what particle size will the valuable minerals be 'freed' or liberated from the gangue. These values form the basis for selecting the sizes that were selected for further characterization and froth flotation. It has also been reported that effective recoveries for different minerals are usually achieved at different particle sizes. Therefore it is imperative to know the economic liberation of minerals before processing by flotation. It is very important to control the crushing and grinding of sample to be floated based on the economic liberation because it has been ascertain that if particles are too fine, it will lead to formation of slime in which case valuable minerals are lost in the tailings. Meanwhile, if the minerals are too large, there will be difficulties in floating the valuable minerals or too much reagent could be needed to attain optimum recovery (this is not ecocnomical).

\section{B. Chemical Composition of Anka sulphide mineral}

Tables 1 and 2 show the results of the elemental composition of the ores with respect to the total elements present within the ore and their distributions within the particle size fractions of $-150+106,106+75,-75+53$ and $-53 \mu \mathrm{m}$ as determined by ICP-OES. Percentage composition of the various elements vary with difference in particle sizes of the deposits. Particle size -75 $+53 \mu \mathrm{m}$ of Anka deposit gave highest weight percentage of $45 \%$ of lead followed by $-53 \mu \mathrm{m}$ which had $44 \%$. Meanwhile, particle size $+150 \mu \mathrm{m}$ of Anka gave the highest weight $\%$ of zinc which is $4.9 \%$. On the other hand, particle size fraction $-53 \mu \mathrm{m}$ of Ishiagu gave highest weight percentage of $50.0 \%$ lead followed by $-75+53 \mu \mathrm{m}$ which is $44 \%$.

TABLE I: CHEMICAL COMPOSITION OF ANKA SULPHIDE ORE

\begin{tabular}{lllll}
\hline $\begin{array}{l}\text { Particle size } \\
\text { range }\end{array}$ & \multicolumn{5}{l}{ Elements \% weght } \\
\hline & $\mathrm{Pb}$ & $\mathrm{Zn}$ & $\mathrm{Fe}$ & $\mathrm{Cu}$ \\
$-150+106$ & 15.0 & 4.9 & 17.0 & 14.0 \\
$-106+75$ & 20.0 & 3.6 & 5.2 & 17.0 \\
$-75+53$ & 45.0 & 1.5 & 4.5 & 13.0 \\
-53 & 44.0 & 1.5 & 3.5 & 21.0 \\
\hline
\end{tabular}

\begin{tabular}{|c|c|c|c|c|}
\hline \multirow{2}{*}{$\begin{array}{l}\text { Particle size } \\
\text { range }\end{array}$} & \multicolumn{4}{|c|}{ Elements \% weght } \\
\hline & $\mathrm{Pb}$ & $\mathrm{Zn}$ & $\mathrm{Fe}$ & $\mathrm{Cu}$ \\
\hline$-150+106$ & 20.0 & 3.6 & 5.2 & 1.7 \\
\hline$-106+75$ & 31.0 & 3.6 & 5.2 & 5.6 \\
\hline$-75+53$ & 44.0 & 3.1 & 7.8 & 9.4 \\
\hline-53 & 50.0 & 1.2 & 7.6 & 7.6 \\
\hline
\end{tabular}

Meanwhile, particle size $+150 \mu \mathrm{m}$ gave the highest weight $\%$ of zinc which is $3.6 \%$. This means that the Ishiagu deposit is richer in lead while Anka deposit is richer in zinc. There are also other elements at various percentages within the particle sizes. This variation in elemental distribution could be attributed to difference in the mineralogical characteristics of the deposits. The percentage composition of lead was higher at lower sizes while that of zinc was lower at lower sizes. The reason for this is the fact that galena which is the major ore of lead has good cleavage and fracture and therefore break along its cubes up to Nano particles while sphalerite which is major ore of zinc though has a dodecahedral cleavage and fractures on uneven flat surface. The implication of this is that during the processing as galena breaks along its cubes sphalerite only breaks along flat surface and it poses difficulties in reduction even at higher grinding. The ability of galena to break along its cleavages with its softness and brittleness properties makes its size reduction easy.

\section{X-ray diffraction patterns of Anka and Ishiagu sulphide ores}

$X$ ray diffraction of patterns of particle sizes $-53,-75+53$, and $-106+75 \mu \mathrm{m}$ of Anka and Ishiagu sulphide ores are as shown in Figures 2(a-d). It was revealed that there are variations in their mineralogical compositions. At $-106+75 \mu \mathrm{m}$, Anka (Figure 2a) mineral phases revealed are galena, magnetite, sphalerite, arsenic and quartz while that of Ishiagu (Figure 2b) are galena, anglesite, sphalerite, and quartz at various different percentages. At $-75+53 \mu \mathrm{m}$, phases which were identified for Anka (Figure 2c) are galena, sphalerite, arsenic and quartz, while that of Ishiagu are galena, magnetite and quartz (Figure 2d). A good percentage of the valuable minerals were revealed at $-53 \mu \mathrm{m}$ meaning that a good mineral liberation were attained at that particle size. Since the behaviour of particles in separation processes is a function of different properties of the particles, it therefore means that grinding the ore to $-53 \mu \mathrm{m}$, will enhance the required concentrate grades with reasonable recoveries of valuable minerals. 


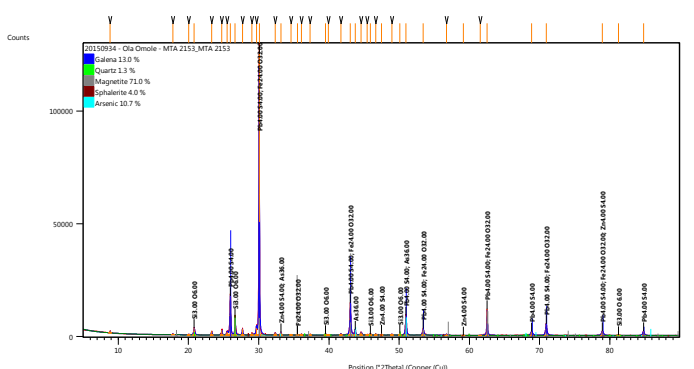

(a)

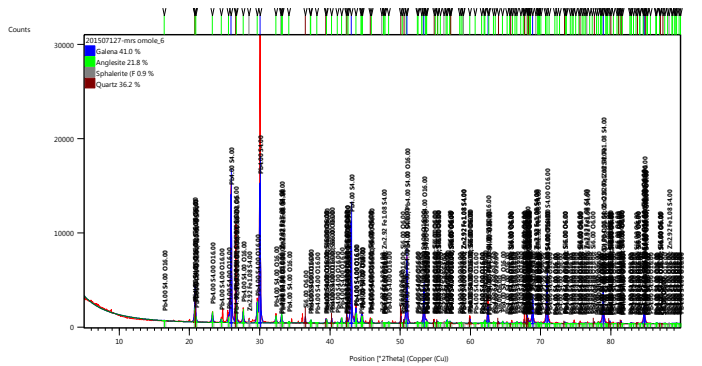

(b)

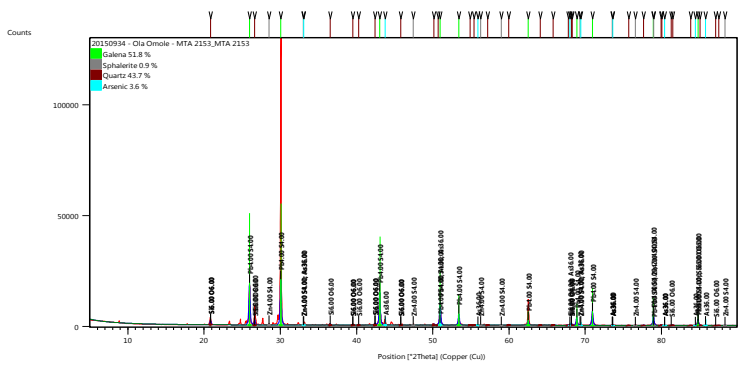

(c)

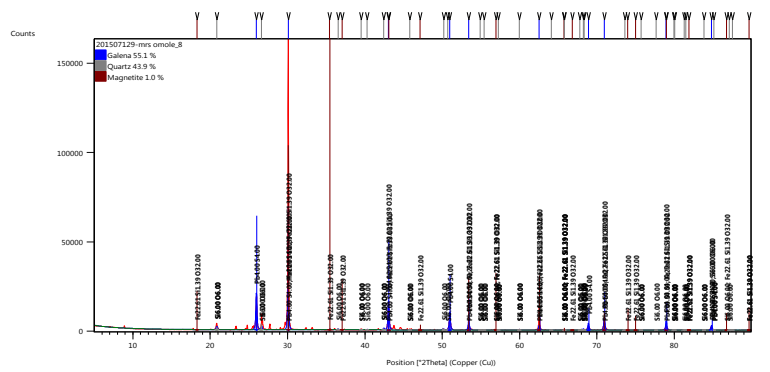

(d)

Fig. 2. X-ray diffraction patterns showing quantitative and qualitative analyses of (a) Anka $-106+75 \mu \mathrm{m}$ (b) Ishiagu -106 $+75 \mu \mathrm{m}$ (c) Anka $-75+53 \mu \mathrm{m}$ (d) Ishiagu $-75+53 \mu \mathrm{m}$

\section{A. Morphological and quantitative analysis of the Anka and} Ishiagu sulphide ores.

Morphological and quantitative analysis of the Anka and Ishiagu sulphide minerals are as shown in Figures 3 and 4. The micrographs of both deposits comprise of large medium and small particles of different irregular shapes. The Tables 3 and 4 show that there is presence of various elements; lead, zinc, molybdenum, sulphur, and oxygen are in the two deposits but in various proportions.

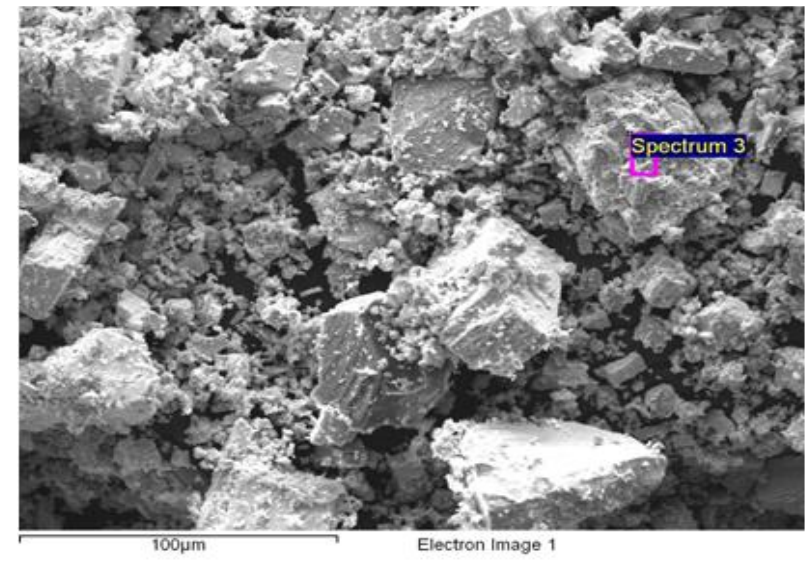

Fig. 3. SEM micrographs Anka sulphide ore

TABLE 3: CHEMICAL COMPOSITION OF ANKA SULPHIDE ORE AT SPECTRUM 3

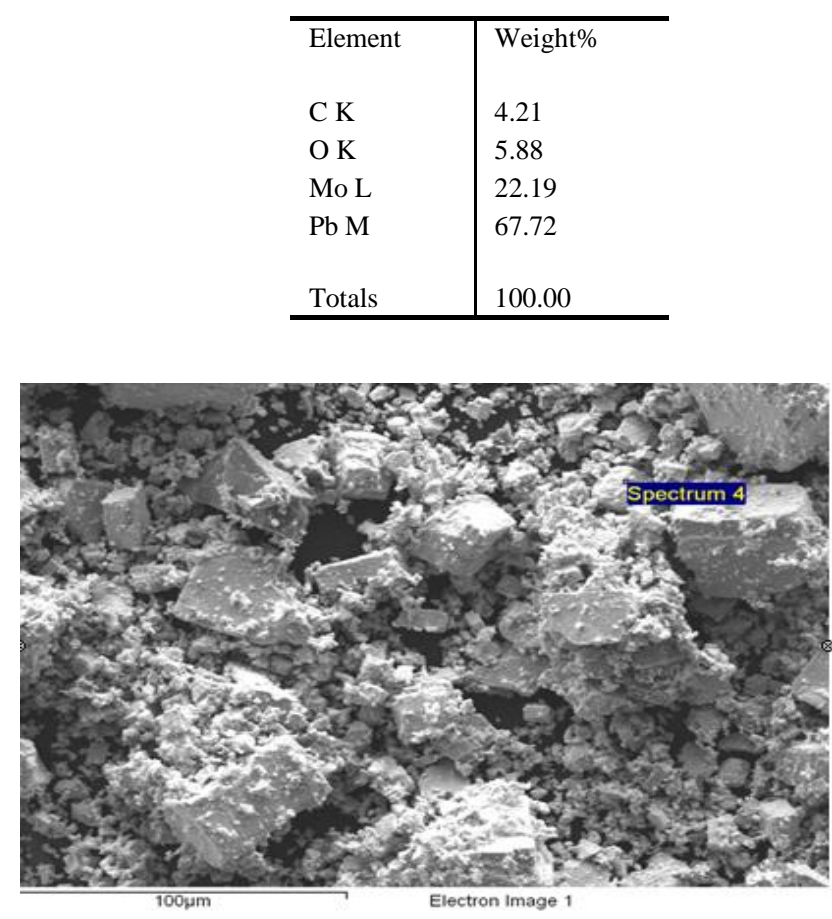

Fig. 4. SEM micrographs Ishiagu sulphide ore

TABLE III: CHEMICAL COMPOSITION OF ISHIAGU SULPHIDE ORE AT SPECTRUM 4

\begin{tabular}{l|l}
\hline Element & Weight\% \\
& \\
$\mathrm{C} \mathrm{K}$ & 10.22 \\
$\mathrm{~S} \mathrm{~K}$ & 14.96 \\
$\mathrm{Zn} \mathrm{L}$ & -0.78 \\
$\mathrm{~Pb} \mathrm{M}$ & 75.59 \\
& \\
Totals & 100.00 \\
\hline
\end{tabular}

\section{B. Flotation experiments}

Figure 5 and 6 show the recovery of lead sulphide concentrate from Anka and Ishiagu sulphide ores with varying collectors; potassium ammyl xanthate, sodium oleate and sodium ethyl xanthate. 


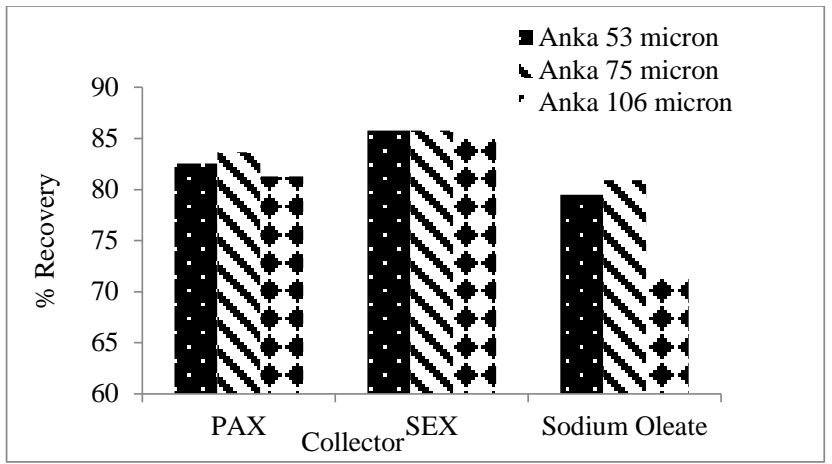

Fig. 5. Recovery of lead sulphide concentrate from Anka sulphide ore with varying collectors

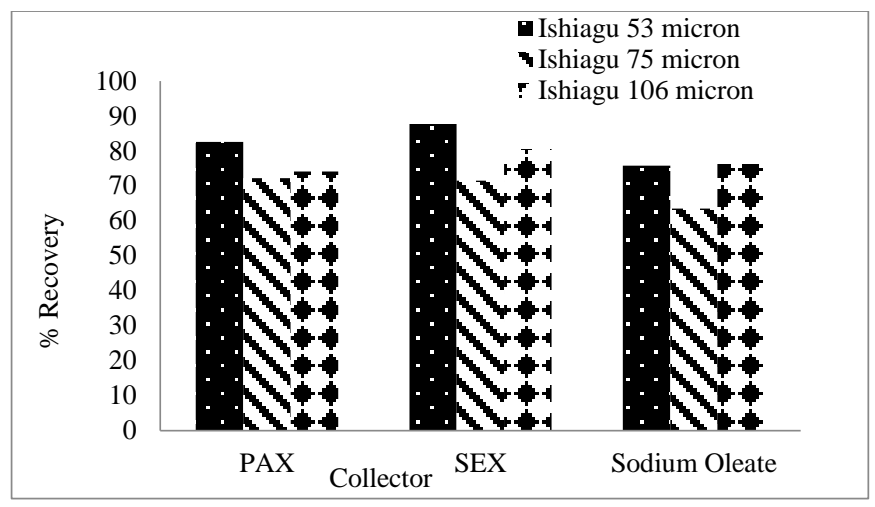

Fig. 6. Recovery of lead sulphide concentrate from Ishiagu sulphide ore with varying collectors

Comparing the recoveries of lead concentrates from both deposits, highest lead recovery of $87.74 \%$ was obtained at particle size fraction $-53 \mu \mathrm{m}$ for Ishiagu ore whilst that of Anka is $85.76 \%$ at the same particle size fraction.

Fig. 7 and 8 show the recovery of zinc sulphide concentrate from Anka and Ishiagu sulphide ores with varying depressants; starch, sodium silicate and potassium dichromate.

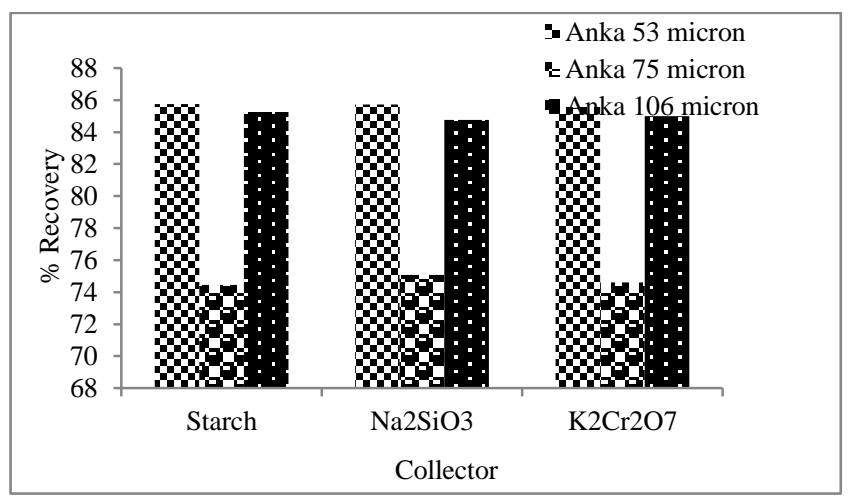

Fig. 7. Recovery of zinc sulphide concentrate from Anka sulphide ore with varying depressants

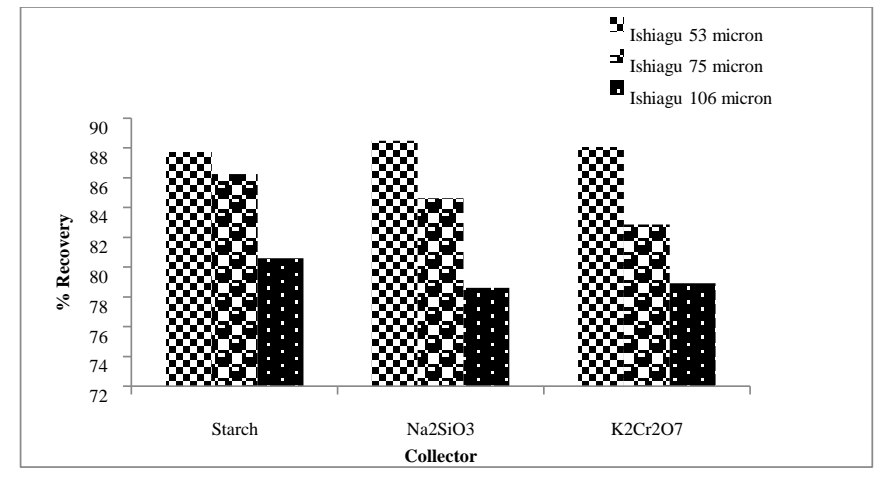

Fig. 8. Recovery of zinc sulphide concentrate from Ishiagu sulphide ore with varying depressants

On the other hand, at the zinc flotation, the highest recovery of $88.48 \%$ was recorded whilst floating Ishiagu ore with sodium silicate and $85.77 \%$ was obtained for Anka ore for material with a PSD of $-53 \mu \mathrm{m}$. The possible reasons for a better recovery with Ishiagu sample could be because of the fact that ishiagu deposit contain greater percentage of lead especially at particle size $-53 \mu \mathrm{m}$ (Tables 1 and 2). Another reason could also be because by the mineralogical analysis via SEM and XRD, Anka deposit contain more of the impurities; Silca, molybdenum, barium and arsenic. Sodium siliate has also been a good $\mathrm{pH}$ modifier and effective depressant of slime in the floation of molybdenite containing $\mathrm{Pb}, \mathrm{Zn}, \mathrm{Cu}$ and $\mathrm{Fe}$ [13].

\section{CONCLUSION}

Comparative effects of mineralogical differences on the flotation behavior of complex sulphide ores from two deposits in Nigeria (Anka- North east and Ishiagu- North West) had been studied. It can be ascertained that the flotation behaviour of any mineral depends on their mineralogical composition. Phases of galena, sphalerite and quartz were revealed for both deposits according to $\mathrm{X}$ ray diffraction patterns. The results obtained show that the range of economic liberation for the two deposits range between -150 and $+106 \mu \mathrm{m}$. It was also shown that the two deposits contain $\mathrm{Pb}, \mathrm{Zn}, \mathrm{Fe}, \mathrm{Cu}, \mathrm{Si}, \mathrm{S}, \mathrm{Na}$. However, Anka deposit revealed the presence of arsenic while Ishiagu revealed magnetite. $\mathrm{Pb}, \mathrm{Zn}, \mathrm{Fe}, \mathrm{Al} \mathrm{Si}$ and copper are common to both deposits while Anka contains barite and molybdenum according to SEM-EDS. There is high potential for recovery of lead and zinc sulphide concentrate from Anka and Ishiagu sulphide ores.

\section{REFERENCES}

[1] E. Whiteman, N.O. Lotter, and S.R Amos, "Process mineralogy as a predictive tool for flowsheet design to advance the Kamoa project," Minerals Engineering, vol. 96, pp.185-193, 2016. https://doi.org/10.1016/j.mineng.2016.05.004

[2] J. Rincon, S. Gaydardzhiev, L. Stamenov, "Investigation on the flotation recovery of copper sulphosalts through an integrated mineralogical approach," Minerals Engineering, vol. 130, pp. 36-47, 2019. https://doi.org/10.1016/j.mineng.2018.10.006

[3] L. Little, Q. Mclennan, A. Prinsloo, K. Muchima, B. Kaputula, and C Siame, "Relationship between ore mineralogy and copper recovery across different processing circuits at Kansanshi mine," Journal of the Southern 
African Institute of Mining and Metallurgy, vol. 118, no. 11, pp.1155-1162, 2018.

https://doi.org/10.17159/2411-9717/2018/v118n11a5

[4] D.J. Vaughan, and C.L. Corkhill, "Mineralogy of sulfides. Elements", vol. 13, no. 2. pp. 81-87. ISSN 1811-5209 https://doi.org/10.2113/gselements.13.2.81, (2017).

[5] N.J. Cook, C.L. Ciobanu, K. Ehrig, A. Slattery, M.R Verdugo-Ihl, L. Courtney-Davies, and W. Gao, "Advances and opportunities in ore mineralogy," Minerals, vol. 7, no. 12, pp.233, 2017. https://doi.org/10.3390/min7120233

[6] I Achaye. Effect of Particle Properties on Froth Stability. Published Thesis of University of Cape Town, 2017.

[7] M. Zanin, H. Lambert, and C.A. du Plessis, "Lime use and functionality in sulphide mineral flotation: A review," Minerals Engineering, vol. 143, pp.105922, 2019.

https://doi.org/10.1016/j.mineng.2019.105922

[8] T Bhambhani. "The Effect of Particle Size and Shape on Transport through Confined Channels in three-phase Froths," Foundation School of Engineering and Applied Science Columbia University, 2019.

[9] F. Nakhaei, and M. Irannajad, "Reagents types in flotation of iron oxide minerals: A review,"Mineral Processing and Extractive Metallurgy Review, vol. 39, no. 2, pp.89-124, 2018 https://doi.org/10.1080/08827508.2017.1391245

[10] A. Pattanaik and R. Venugopal, Role of Surfactants in Mineral Processing: An Overview. DOI: 10.5772/intechopen.85947, 2019. https://doi.org/10.5772/intechopen.85947

[11] U.A. Danbatta, Y.I Abubakar, Y., and A.A. Ibrahim, "Geochemistry of gold deposits in Anka Schist Belt, Northwestern, Nigeria," Nigerian Journal of Chemical Research, vol. 14, pp.19-29, 2009.

[12] N.M. Waziri, and J.E. Andrews, "In vitro bioaccessibility of lead in Artisanal mining contaminated soils and sediments from the Anka area, NW Nigeria," Earth Science Research, vol. 3, no 1, pp.1, 2014. https://doi.org/10.5539/esr.v3n1p1

[13] C.H. Park, and H.S. Jeon, "The effect of sodium silicate as $\mathrm{pH}$ modifier and depressant in the froth flotation of molybdenite ores,"Materials transactions, vol. 51, no. 7, pp.1367-1369, 2010. https://doi.org/10.2320/matertrans.M2009397 